Correction

\title{
Correction: Yuan, G., et al. A Microgripper with a Post-Assembly Self-Locking Mechanism. Sensors 2015, 15, 20140-20151
}

\author{
Guangmin Yuan, Weizheng Yuan, Yongcun Hao, Xiaoying Li and Honglong Chang * \\ Received: 7 January 2016; Accepted: 7 January 2016; Published: 8 January 2016 \\ Academic Editor: Vittorio M. N. Passaro \\ Key Laboratory of Micro/Nano Systems for Aerospace, Ministry of Education, \\ Northwestern Polytechnical University, Xi'an 710072, China; yuangm@nwpu.edu.cn (G.Y.); \\ yuanwz@nwpu.edu.cn (W.Y.); haoyongcun@126.com (Y.H.); xiaoy@nwpu.edu.cn (X.L.) \\ * Correspondence: changhl@nwpu.edu.cn; Tel.: +86-29-8846-0353; Fax: +86-29-8849-2841
}

The authors wish to make the following correction to this paper [1]:

The author name "Xiaoyi Li" should be changed into "Xiaoying Li".

The authors would like to apologize for any inconvenience caused to the readers by this change.

Conflicts of Interest: The authors declare no conflicts of interest.

\section{References}

1. Yuan, G.; Yuan, W.; Hao, Y.; Li, X.; Chang, H. A Microgripper with a Post-Assembly Self-Locking Mechanism. Sensors 2015, 15, 20140-20151. [CrossRef] [PubMed]

(C) 2016 by the authors; licensee MDPI, Basel, Switzerland. This article is an open access article distributed under the terms and conditions of the Creative Commons by Attribution (CC-BY) license (http://creativecommons.org/licenses/by/4.0/). 